\title{
Impact of Congenital Heart Disease on School Adjustment in Elementary School Aged Children
}

\author{
Jingyi (Alana) Yang ${ }^{1}$ and Kerri L. Modry-Mandell ${ }^{2}$ \\ ${ }^{1}$ Mercer Island High School, Mercer Island, WA, USA \\ ${ }^{2}$ Tufts University, Medford, MA, USA
}

\section{ABSTRACT}

Congenital heart disease or congenital heart defect (CHD) is an abnormality of the heart that develops before birth (American Heart Association, 2018). While much is known about how children are physically affected, less is known about the psychological impacts of CHD. In particular, little is known about school adjustment or the process of adapting to the role of a student and to various aspects of the school environment, while failure to adjust can cause academic and social-emotional problems (Lakhani, Jain, \& Chandel, 2017). This review aims to investigate how and to what extent having CHD affects school adjustment in elementary school aged children (grades 1-5) (a group oftentimes overlooked as insignificant) and if the severity of CHD in elementary-aged children impacts their ability to adjust in schools. By reviewing literal and studies published in the past 50 years, the review reaches the conclusion that CHD does have negative effects on school adjustment and the severity of CHD positively correlates with difficulty to adjust. The purpose of this paper is to provide insight into the current studies regarding children with CHD and their relationship to different aspects of school and the school environment as well as propose a study that is multisite, multi-informant, and multi-method. The result of this review has compelling clinical and theoretical significance, benefiting clinicians and practitioners, teachers and educators, and researchers by bridging the gap between existing and unknown knowledge of elementary-aged children with CHD and their school adjustment.

\section{Introduction}

Congenital heart disease or congenital heart defect (CHD) is an abnormality of the heart that develops before birth (American Heart Association, 2018). It can vary from small holes in the heart to missing or poorly developed parts. Most heart defects either cause an abnormal blood flow through the heart or obstruct blood flow in the heart or blood vessels (Johns Hopkins Medicine). Obstructive defects, septal defects, and cyanotic defects are some types of CHD. While there could be no symptoms, some of the common symptoms in infants and children include cyanosis, fast breathing, poor weight gain, swelling, and fainting during exercise (United Kingdom National Health Service [NHS], 2018). 

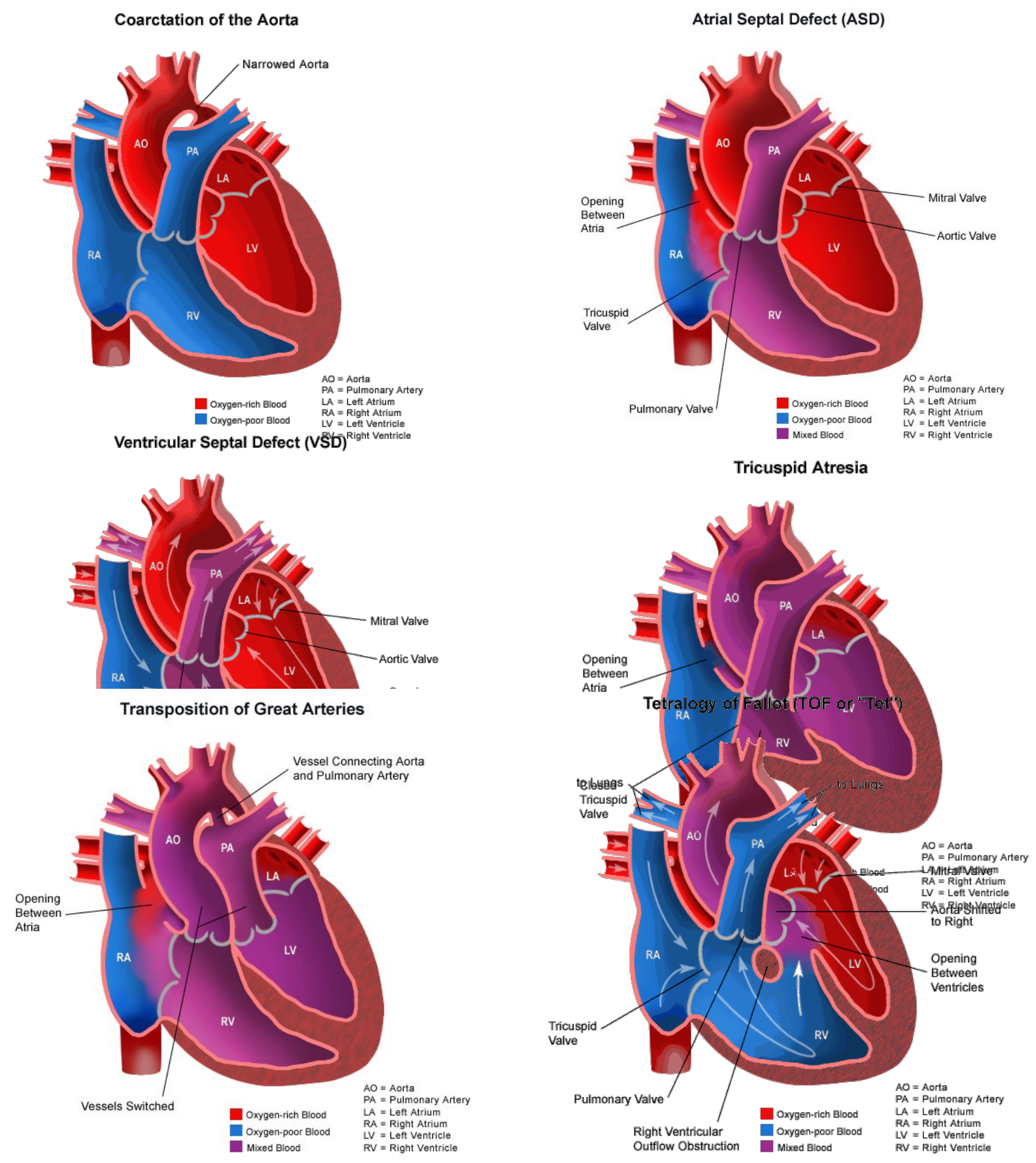

Figure 1

Different types of CHD

CHD affects 1\% of children born each year in the US (Centers for Disease Control and Prevention ([CDC], 2019). According to Gilboa et al. (2016), there were an estimated 2.4 million people living with CHDs in the United States in 2010, and nearly 300,000 of those people had severe CHDs. Those with severe CHD require surgery or other procedures in the first year of life (CDC, 2019). The cause is unknown in most cases, but viral infection in the mother, genetics, and the use of drugs and alcohol can result in CHDs (Johns Hopkins Medicine). 
In 2010, Gilboa et al. found that the mortality rate resulting from CHD declined by 24.1\% overall from 1999 to 2006. With technological advancements, children and adults with CHD can live longer and healthier lives. A fetal echocardiogram allows cardiologists to diagnose CHD prenatally using ultrasound; echocardiograms, chest X-rays, pulse oximetry, cardiac catheterization, and cardiovascular magnetic resonance imaging (MRI) also assist in the diagnosis of CHD (Mayo Clinic, 2018). Short term treatments include procedures using catheterization, open-heart surgery, heart transplant, and medications, while long-term treatment includes lifelong monitoring, exercise restrictions, and infection prevention (Mayo Clinic, 2018). Patients who receive such treatment have better outcomes (University of Minnesota Masonic Children's Hospital, 2019).

Researchers study and gain insight into the psychological impacts of congenital heart disease (CHD). Most of the current research focuses on the quality of life (QoL) of children and adolescents with CHD (Sertçelik, Alkan, Sapmaz, Coşkun, \& Eser, 2018; Latal, Helfricht, Fischer, Bauersfeld, \& Landolt, 2009; Areias et al., 2013) . For example, Latal et al. (2009) found that a significant proportion of survivors of open-heart surgery for CHD are at risk for psychological maladjustment and impaired QoL. Another study found that female patients and patients with worse academic performance and poor social support have lower levels of psychosocial adjustment (PSA) and QoL (Areias et al., 2013). Thus far, no single study has comprehensively connected CHD and school adjustment in school-aged children and found an association between the two. A considerable amount of research (Areias et al., 2013; Awaad \& Darahim, 2014; Teixeira et al., 2011) focuses on teens and adolescents; therefore, it is helpful to shed light on schoolaged children in order to gain insight into their developmental needs.

Elementary school aged children (grades 1-5) exhibit tremendous physical growth and cognitive and emotional development (Collins, 1984). The major developmental milestones in elementary school aged children are to acquire basic competencies like reading, writing, and computation. The schooling process also has profound impacts on children socially. School adjustment is the process of adapting to the role of a student and to various aspects of the school environment. Failure to adjust can cause academic and social-emotional problems (Lakhani, Jain, \& Chandel, 2017). School adjustment also encompasses social motivation in the form of goal pursuit, behavioral competence, and positive interpersonal relationships (Wentzel, 2003). Effective school adjustment depends on factors like social wellness, emotional behavior, and academic skills which help children participate in the school environment (Lakhani, Jain, \& Chandel, 2017). School adjustment will be discussed in regards to both academics and social adjustment (such as interactions with peers). This paper will provide insight into the areas that have not been looked at before. Furthermore, this review is going to be conducted through a developmental psychopathology (DP) lens that considers typical vs. atypical development, integrative contexts, and risk factors.

\section{Question}

How and to what extent does having congenital heart disease (CHD) affect school adjustment in elementary school aged children (grades 1-5)? Does the severity of CHD in elementary aged children impact their school adjustment?

\section{Hypothesis}

Elementary school aged children with congenital heart disease (CHD) have lower levels of school adjustment (academically and psychosocially). In addition, children with more severe CHD are impacted more profoundly than children who do not have severe CHD.

\section{Literature Review}

This section will provide an overview and analysis of the work that has been done on school adjustment and children with congenital heart disease (CHD) in the last 50 years. Literature will be divided into themes including teacher-child 
relationships and school adjustment; peer relationships and school adjustment; elementary school aged children (grades 1-5) and school; and children with more severe CHD.

\section{Teacher-child relationships and school adjustment}

Teachers play a vital role at school; they are educators, mentors, and role models. Examining teacher-student relationships helps paint a big picture of how teacher-student relationship differs with children with CHD, therefore impacting school adjustment. A study conducted by Baker in 2006 demonstrates the extent teacher-student relationship contributes to school adjustment. Positive teacher-child relationships provide children with the emotional security necessary to engage fully in learning activities and to scaffold the development of key social, behavioral, and self- regulatory competencies needed in the school environment (Pianta, 1999). According to Baker (2006), the teacher-child relationship in elementary school is a potential mediator or moderator of the process of possessing and acknowledging capabilities to do well in school. Baker's study includes 1310 kindergarten through fifth-grade students and 68 teachers from corresponding schools. He used the Student-Teacher Relationship Scale (STRS), the Behavior Assessment System for Children-Teacher Rating Scales for Children (BASC TRS-C), and the student's standardized test scores and report cards to form an analysis. Results show that closeness in the student-teacher relationship indicates moderately higher reading grades and positive work habits and a more significant association with the development of social skills, while conflicts show a negative correlation for school outcomes and a lower correlation with standardized test scores (Baker, 2006).

Another study conducted by Jerome, Hamre, and Pianta (2008) examined general trends in teacher-reported conflicts and closeness among 878 children from kindergarten through sixth grade. They discovered meaningful correlations such as how different teacher's perceptions of conflict are relatively more stable over the first seven years of school than different teacher's perceptions of closeness (Jerome, Hamre, \& Pianta, 2008). Additionally, teacher ratings of conflict at each grade were negatively correlated with maternal education, maternal sensitivity, HOME scores (Home Observation for Measurement of the Environment), and academic achievement (Jerome, Hamre, \& Pianta, 2008). The researchers also found that average levels of teacher-reported conflict increased between kindergarten and fifth grade while average closeness decreases. In addition, male children experienced greater decreases in early teacher-reports of closeness than female students, resulting in an increasing gap of student-teacher relationship between males and females toward middle elementary school.

The studies above show an array of factors and trends of student-teacher relationships, which are a very important part of the schooling experience. There are even more challenges with children with CHD. In reality, typical education systems aren't designed for children with chronic illness to adjust because most educators lack the understanding of the needs of children with medical conditions in the classroom due to the lack of training (Irwin \& Elam, 2011). With limited knowledge, educators often don't respond to acute health episodes well and therefore create educational barriers and eliminate the possibility of an equitable educational experience for students with an illness (Irwin \& Elam, 2011). These challenges pose difficulties in the school adjustment of children with CHD; the following section will cover and examine the specifics of these challenges.

\section{Peer relationships and school adjustment}

Chronically victimized children are at risk for maladaptive outcomes in childhood and adolescence, including loneliness and poor school achievement (Buhs, Ladd, \& Herald 2006). Risky relationships and behavior could evolve into maltreatment and eventually lead to disengagement and change in social adjustment. According to the study conducted by Buhs, Ladd, \& Herald (2006) which examines 380 children ages 5 through 11, social withdrawal predicted chronic exclusion only and indicated that children exhibiting socially withdrawn behavior were more likely to be excluded by peers across grades. Children who are chronically excluded tend to increase their avoidance of school. The researchers 
corroborated previous studies and reached the conclusions that children who were less accepted by their kindergarten classmates were put to greater risk for peer maltreatment in subsequent grades, chronic peer maltreatment throughout the primary school years predicted later school disengagement, and peer group rejection in kindergarten is associated with children's achievement during the middle grade school years (the association is mediated principally by their exposure to chronic peer exclusion and decelerating classroom participation) (Buhs, Ladd, \& Herald, 2006).

Academic engagement is defined as the ways and extent to which students are committed to or involved in school and represents daily interactions between students and their learning contexts, which is supported by peer relationships (Fredricks, Blumenfeld, \& Paris, 2004). Peers provide psychosocial and academic resources that enhance individual students 'academic outcomes hence making it a vital factor of school adjustment (Dika \& Singh, 2002). Because children with CHD are more prone to withdrawal and have limitations on physical exercise (e.g. the ability to do sports), they are more likely to become targets for peer alienation. This paper will provide an analysis of how peer relationship factors into the equation of school adjustment for children with CHD.

\section{Elementary school aged children (grades 1-5) and school}

There are many tasks that children perform and abilities that they acquire at school. In Collins 'book Development During Middle Childhood: The Years From Six to Twelve (1984), he discusses the effects of schools and schooling on children grades 1-5 (which is also referred to as middle childhood). During the middle childhood years, basic literacy and computational and conceptual skills are acquired. Children also develop relatively permanent attitudes about schools and learning, including study habits. The most universally recognized function of schools is to "impart knowledge and skills that will enable the learner to participate successfully in the society's institutions" while "schools by virtue of their structure also facilitate normative outcomes" regarding the social aspect (Collins, 1984, p. 284). During middle childhood, children's ability to use images, symbols, concepts, and rules increases, as does their vocabulary. There is also a stated positive correlation between self-esteem, associating self-image with academics, and academic performance (Collins, 1984). Teacher behavior also impacts self-confidence. On the social aspect, children learn to be independent achievers, to accept universal standards, and to function well as group members during school (Collins, 1984). Furthermore, children gain cognitive control with an "increasing ability to respond selectively to stimuli and begin to process and understand material effectively" (Mah \& Ford-Jones, 2012, p. 82). Their feelings also transform from an "inward view of the world to an outward view," meaning they start to become more aware of their own feelings and notice how they are different from others (Mah \& Ford-Jones, 2012, p. 82). At school, rewards are based on individual performance because children have different abilities and levels of preparedness for school. Although there are many other factors that affect children's relationship with school, children with CHD definitely have different schooling experiences than children without CHD, making their school adjustment process also different.

\section{Children with more severe CHD}

According to a study conducted by Casey, Sykes, Craig, Power, \& Mulholland (1996) that compares 26 children with surgically treated complex CHD and 26 children who were diagnosed as having an innocent heart murmur, the children with more complex CHD are rated by their parents to be more withdrawn, have more social problems, and engage in fewer activities, and they are rated by their teachers to be more withdrawn. They also found that there is an evident but not significant teacher rating that children with complex CHD perform less well and work less hard than their counterparts with non-complex CHD (Casey, Sykes, Craig, Power, \& Mulholland,1996). In addition, the five measures of school adjustment (academic performance, working, behaving, learning, and happiness) do not significantly differ from the experimental and control groups (Casey, Sykes, Craig, Power, \& Mulholland,1996). There is a higher incidence of children with complex CHD performing academically in the clinical or borderline clinical range. 
Parents rate children with complex CHD as less engaged in activities compared to the children in the control group. Withdrawn behavior, somatic complaints, and social problems are also identified as significant. Exercise duration was expectedly different between the two groups. In addition, children with complex CHD have a greater impact on their families, including financial struggle and stress. Another interesting finding is that children with complex CHD are not rated by their teachers and parents to be more inattentive or to have any significant academic problems. This study concludes that children with complex CHD have more problems with withdrawal and somatic complaints, which are more related to the social aspects of school adjustment. However, it is not exactly clear how these problems would impact the social adjustment and peer interactions at school, which this paper will focus on.

Another study by Ryberg, Sunnegårdh, Thorson, \& Broberg (2016) focuses on the intellectual functioning of children with congenital heart disease treated by surgery or catheter intervention. Two hundred twenty-eight children were tested on the Wechsler intelligence scales, evaluated by their full-scale IQ (FSIQ), and then analyzed by age and the severity of the diagnosis. Three groups of children with mild, moderate, and severe CHD were recruited. The researchers found no significant differences between boys and girls; however, they found that children with severe CHD have significantly lower FSIQ numbers than children with mild or moderate CHD. Intellectual functioning is also found to be notably lower in 9-year-olds and 15-year-olds than in 3-year-olds with severe CHD although intellectual functioning supposedly increases as students get older. These findings support the hypothesis that children with more severe CHD may have more difficulties and challenges adapting to the academic aspect of school adjustment.

\section{Conclusion}

The results from this review support the hypothesis that elementary school aged children with congenital heart disease (CHD) have lower levels of school adjustment (academically and psychosocially) while the severity of CHD positively correlates with difficulty to adjust. In the review, the two main aspects of school adjustment, which are teacher-child relationship and peer relationship, were analyzed, while how elementary aged children adjust to the school environment and how children with more severe CHD fit into the picture were examined.

\section{Discussion}

This paper explores the impacts of living with congenital heart disease (CHD) in elementary aged children (grades 15) and specifically focusing on school adjustment. Due to technological advancements, researchers are now able to gain further understanding of aspects of the lives of those living with CHD. Elementary-aged children are oftentimes overlooked as insignificant in the research world. The aim of this review paper is to provide insight into the current studies regarding children with CHD and their relationship to different aspects of school and the school environment. There will be advancing to the current work in the field.

\section{Limitations}

Because the topic of school adjustment in relation to CHD is not yet well understood, there are limited literature and studies that cover this topic. The literature examined in this review is not only limited to studies conducted, but also books written within the past fifty years. In addition, the study proposed in the future directions section could not be performed due to limitations of the authors credentials as a high school student. Therefore, in order to corroborate the results of this study and increase its significance, it is best if future studies like the one outlined below is performed and/or altered. However, this does not mean the review does not carry any significance since it explores a topic that is not thoroughly understood and synthesizes important research performed in the past. 


\section{Clinical Significance}

The results and conclusions of this review have compelling clinical and theoretical significance. For clinicians and practitioners, the results help inform them and will aid them in their practice and treatment involving children with CHD. These professionals will have a more solid understanding of the psychological effects of the disease. Furthermore, the results of the review can potentially connect with other chronic illnesses and may assist in the understanding of how having a chronic illness affects the school adjustment of children. For teachers and educators, the result is also a great benefit. Selekman's study in 2016 regarding the challenges of students with chronic conditions and the challenges of regular education teachers concluded that teachers want to be informed about their students with chronic conditions, but they lack information about the conditions due to a lack of preparation in pre teacher education programs about students with chronic conditions. However, teachers share concerns about their students and possess the desire to help their students (Selekman, 2016). Given appropriate knowledge and training, teachers will not only be able to become more prepared and play their roles at school much more effectively for children with CHD, but also for children with other types of chronic illness. The result also benefits researchers who want to further the studies and knowledge in children with CHD and their school adjustment.

\section{Future Studies}

Future studies can be performed to corroborate and further the results of this review. Upcoming research needs to conduct detailed studies in elementary aged children (grades 1-5) with congenital heart disease (CHD). It is recommended that future researchers incorporate evaluation tools such as the student Student Teacher Relationship Scales (STRS) (Pianta, 1992), the CAYCI Academic Motivation Scale (AMS), and the CAYCI Peer Relationships Scale (PRS) for reliability (Anderson-Butcher, Amorose, Iachini, \& Ball, 2015, 2016). It is also recommended that researchers implement a mixed method study, using both qualitative and quantitative designs.

\section{Acknowledgments}

I want to thank Dr. Modry-Mandell from Tufts University for her guidance and mentorship on this paper. I also want to thank my family for their love and support during the process.

\section{References}

American Heart Association. (2018). About Congenital Heart Defects. Www.Heart.Org. https://www.heart.org/en/health-topics/congenital-heart-defects/about-congenital-heart-defects

Anderson-Butcher, D., \& Amorose, A. J. (2016). Community and Youth Collaborative Initiative School Experience Surveys: Academic Motivation Scale in Elementary School Students. Columbus, OH: College of Social Work, The Ohio State University.

Anderson-Butcher, D., Amorose, A.J., Iachini, A., \& Ball, A. (2015). Community and Youth Collaborative Institute School Experience Surveys: Peer Relationship Scale in Elementary School. Columbus, OH: College of Social Work, The Ohio State University.

Areias, M. E., Pinto, C. I., Vieira, P. F., Teixeira, F., Coelho, R., Freitas, I., Matos, S., Castro, M., Sarmento, S., Viana, V., Quintas, J., \& Areias, J. C. (2013). Long term psychosocial outcomes of congenital heart disease (CHD) in 
adolescents and young adults. Translational pediatrics, 2(3), 90-98. https://doi.org/10.3978/j.issn.2224$\underline{4336.2013 .06 .02}$

Awaad, M. I., \& Darahim, K. E. (2015). Depression and anxiety in adolescents with congenital heart disease. Middle East Current Psychiatry, 22(1), 2-8. https://doi.org/10.1097/01.XME.0000457325.90630.4f

Baker, J. A. (2006). Contributions of teacher-child relationships to positive school adjustment during elementary school. Journal of School Psychology, 44(3), 211-229. https://doi.org/10.1016/j.jsp.2006.02.002

Beacham, B. L., \& Deatrick, J. A. (2015). Children With Chronic Conditions: Perspectives on Condition Management. Journal of Pediatric Nursing, 30(1), 25-35. https://doi.org/10.1016/j.pedn.2014.10.011

Bengtsson, M. (2016). How to plan and perform a qualitative study using content analysis. NursingPlus Open, 2, 814. https://doi.org/10.1016/j.npls.2016.01.001

Buhs, E. S., Ladd, G. W., \& Herald, S. L. (2006). Peer exclusion and victimization: Processes that mediate the relation between peer group rejection and children's classroom engagement and achievement? Journal of Educational Psychology, 98(1), 1-13. https://doi.org/10.1037/0022-0663.98.1.1

Casey, F. A., Sykes, D. H., Craig, B. G., Power, R., \& Mulholland, H. C. (1996). Behavioral Adjustment of Children with Surgically Palliated Complex Congenital Heart Disease. Journal of Pediatric Psychology, 21(3), 335-352. https://doi.org/10.1093/jpepsy/21.3.335

Centers for Disease Control and Prevention. (2019). What are Congenital Heart Defects? | CDC. https://www.cdc.gov/ncbddd/heartdefects/facts.html

Collins, W. A., (1984). Development During Middle Childhood: The Years From Six to Twelve. Washington, DC: The National Academies Press. https://doi.org/10.17226/56.

David Vainberg, L., Vardi, A., \& Jacoby, R. (2019). The Experiences of Parents of Children Undergoing Surgery for Congenital Heart Defects: A Holistic Model of Care. Frontiers in Psychology, 10, 1-14.

https://doi.org/10.3389/fpsyg.2019.02666

Dika, S. L., \& Singh, K. (2002). Applications of Social Capital in Educational Literature: A Critical Synthesis. Review of Educational Research, 72(1), 31-60. https://doi.org/10.3102/00346543072001031

Elo, S., \& Kyngäs, H. (2008). The qualitative content analysis process. Journal of Advanced Nursing, 62(1), 107115. https://doi.org/10.1111/j.1365-2648.2007.04569.x

Fredricks, J. A., Blumenfeld, P. C., \& Paris, A. H. (2004). School Engagement: Potential of the Concept, State of the Evidence. Review of Educational Research, 74(1), 59-109. https://doi.org/10.3102/00346543074001059

Gilboa, S. M., Devine, O. J., Kucik, J. E., Oster, M. E., Riehle-Colarusso, T., Nembhard, W. N., Xu, P., Correa, A., Jenkins, K., \& Marelli, A. J. (2016). Congenital Heart Defects in the United States. Circulation, 134(2), $101-109$. https://doi.org/10.1161/circulationaha.115.019307 
Gilboa, S. M., Salemi, J. L., Nembhard, W. N., Fixler, D. E., \& Correa, A. (2010). Mortality Resulting From Congenital Heart Disease Among Children and Adults in the United States, 1999 to 2006. Circulation, 122(22), 22542263. https://doi.org/10.1161/circulationaha.110.947002

Irwin, M. K., \& Elam , M. (2011). Are We Leaving Children with Chronic Illness Behind? Physical Disabilities: Education and Related Services, 30(2), 67-80. https://files.eric.ed.gov/fulltext/EJ955447.pdf

Jerome, E. M., Hamre, B. K., \& Pianta, R. C. (2009). Teacher-Child Relationships from Kindergarten to Sixth Grade: Early childhood predictors of teacher-perceived conflict and closeness. Social development (Oxford, England), 18(4), 915-945. https://doi.org/10.1111/j.1467-9507.2008.00508.x

Johns Hopkins Medicine. (n.d.). Congenital Heart Defects. Www.Hopkinsmedicine.Org. https://www.hopkinsmedicine.org/health/conditions-and-diseases/congenital-heart-defects

Lakhani, P. K., Jain, K., \& Chandel, P. K. (2017). School Adjustment, Motivation and Academic Achievement among Students . International Journal of Research in Social Sciences, 7(10), 333-348. https://www.researchgate.net/publication321741311 School Adjustment Motivation and Academic Achievement among Stu$\underline{\text { dents }}$

Mah, V. K., \& Ford-Jones, E. L. (2012). Spotlight on middle childhood: Rejuvenating the 'forgotten years'. Paediatrics \& child health, 17(2), 81-83. https://doi.org/10.1093/pch/17.2.81

Mhealth.Org. https://www.mhealth.org/childrens/blog/2019/feb-2019/advancements-congenital-heart-disease-careleading-to-longer-lives-better-outcomes

Pianta, R. C. (1999). Enhancing relationships between children and teachers. American Psychological Association. https://doi.org/10.1037/10314-000

Pianta, R. C., \& Steinberg, M. (1992). Teacher-child relationships and the process of adjusting to school. New Directions for Child and Adolescent Development, 1992(57), 61-80

Ryberg, C., Sunnegårdh, J., Thorson, M., \& Broberg, M. (2016). Intellectual Functioning in Children with Congenital Heart Defects Treated with Surgery or by Catheter Interventions. Frontiers in pediatrics, 4, 113. https://doi.org/10.3389/fped.2016.00113

Selekman J. (2017). Students With Chronic Conditions: Experiences and Challenges of Regular Education Teachers. The Journal of school nursing: the official publication of the National Association of School Nurses, 33(4), 307315. https://doi.org/10.1177/1059840516674053

Sertçelik, T., Alkan, F., Sapmaz, Ş. Y., Coşkun, Ş., \& Eser, E. (2018). Life quality of children with congenital heart diseases. Turk pediatri arsivi, 53(2), 78-86. https://doi.org/10.5152/TurkPediatriArs.2018.6428

Stanford Health Care. (n.d.-a). Atrial Septal Defect (ASD) [Diagram]. Septal Congenital Heart Defects. https://stanfordhealthcare.org/content/shc/en/medical-conditions/blood-heart-circulation/congenital-heart-defects/types/septalcongenital-heart-defects/ jer content/tab-nav-component/tab-nav-parsys/image.img.jpg/1551298380679.jpg Stanford Health Care. (n.d.-b). Coarctation of the Aorta [Diagram]. Obstructive Congenital Heart Defects. https://stanfordhealthcare.org/content/shc/en/medical-conditions/blood-heart-circulation/congenital-heart- 
defects/types/obstructive-congenital-heart-defects/ jer content/tab-nav-component/tab-nav-parsys/image.img.gif/1551299108869.gif

Stanford Health Care. (n.d.-c). Tetralogy of Fallot (TOF or "Tet”) [Diagram]. Cyanotic Congenital Heart Defects. https://stanfordhealthcare.org/content/shc/en/medical-conditions/blood-heart-circulation/congenital-heart-defects/types/cyanotic-congenital-heart-defects/ jcr content/tab-nav-component/tab-nav-parsys/image.img.gif/1551297931857.gif

Stanford Health Care. (n.d.-d). Transposition of Great Arteries [Diagram]. Cyanotic Congenital Heart Defects. https://stanfordhealthcare.org/content/shc/en/medical-conditions/blood-heart-circulation/congenital-heart-defects/types/cyanotic-congenital-heart-defects/ jcr content/tab-nav-component/tab-nav-parsys/image 847246889.img.jpg/1551298025827.jpg

Stanford Health Care. (n.d.-e). Tricuspid Atresia [Diagram]. Cyanotic Congenital Heart Defects. https://stanfordhealthcare.org/content/shc/en/medical-conditions/blood-heart-circulation/congenital-heart-defects/types/cyanotic-congenital-heart-defects/ jcr content/tab-nav-component/tab-nav-parsys/image 1390694557.img.gif/1551298015802.gif Stanford Health Care. (n.d.-f). Ventricular Septal Defect (VSD) [Diagram]. Septal Congenital Heart Defects. https://stanfordhealthcare.org/content/shc/en/medical-conditions/blood-heart-circulation/congenital-heart-defects/types/septal-congenital-heart-defects/ jor content/tab-nav-component/tab-nav-parsys/image 1335541557.img.gif/1551298396794.gif

Teixeira, F. M., Coelho, R. M., Proença, C., Silva, A. M., Vieira, D., Vaz, C., Moura, C., Viana, V., Areias, J. C., \& Areias, M. E. (2011). Quality of life experienced by adolescents and young adults with congenital heart disease. Pediatric cardiology, 32(8), 1132-1138. https://doi.org/10.1007/s00246-011-0039-0

United Kingdom National Health Service. (2018, June 12). Symptoms. Nhs.Uk. https://www.nhs.uk/conditions/congenital-heart-disease/symptoms/

University of Minnesota Masonic Children's Hospital. (2019, February 20). Advancements in congenital heart disease care are leading to longer lives, better outcomes.

Wentzel, K. R. (2003). School adjustment. In W. M. Reynolds \& G. E. Miller (Eds.), Handbook of psychology: Educational psychology, Vol. 7 (p. 235-258). John Wiley \& Sons Inc. 